\title{
Integration of Routine Parental Request of Organ Donation in End-of-Life Care of Children with Neurologic Disorders in the UK: Unresolved Medical, Legal, Cultural, and Religious Challenges
}

Mohamed Y. Rady*

(C) 2020 Springer Science+Business Media, LLC, part of Springer Nature and Neurocritical Care Society

\begin{abstract}
The UK adopted the opt-out system (deemed or presumed consent) in end-of-life organ donation enforceable in May 2020. Presumed consent applies to adults but not children. Transplant advocates have recommended that all children on end-of-life care should be referred for potential organ donation to increase the supply of transplantable organs in the UK. To buttress this objective, a UK survey of parents of deceased children mostly with neurologic disorders secondary to severe brain injuries recommended the integration of routine parental discussion of donation regardless of donation eligibility in end-of-life care. Donation discussions emphasize the utility and suitability of organs in dying children for transplantation to maximize consent rate. To ensure that this recommendation does not harm children and parents, contemporary medical, legal, cultural, and religious challenges to end-of-life organ donation should be disclosed in parental discussion of donation and resolved appropriately. To that effect, it is urged that: (1) practice guidelines for the diagnosis and treatment of neurologic disorders secondary to severe brain injuries in children are updated and aligned with recent advances in neuroscience to eliminate potential errors from premature treatment discontinuation and/or incorrect diagnosis of death by brain(stem) criteria, (2) transparent and non-biased disclosure of all empiric information when discussing donation to ensure informed parental decision-making, and (3) a societal dialogue is conducted on the legal, cultural, and religious consequences of integration of routine donation discussion and referral in end-of-life care of children in the UK.
\end{abstract}

Keywords: Children, End-of-life care, Opt-out system, Organ donation, Pediatrics, Practice guidelines, Presumed consent, UK

\section{Organ Donation in the UK}

The UK adopted the opt-out system (deemed consent) for end-of-life organ donation starting in May 2020 [13]. Deemed (presumed) consent applies to adults but not children. The National Health Service Blood and

*Correspondence: rady.mohamed@mayo.edu

Department of Critical Care Medicine, Mayo Clinic Hospital, 5777 East Mayo Blvd, Phoenix, AZ 85054, USA
Transplant organization regulates the process of organ donation in the UK [2]. Clinical team leaders and specialist nurses for organ donation associated with the National Health Service Blood and Transplant organization are engaged in donation referral and consent [4, 5]. Healthcare professionals identify potential donors in pediatric intensive care units and make the referral to specialist nurses for donation discussion and consent from the parents. The referral criteria for organ donation 
include either: (1) the declaration of death by brain(stem) criteria in heart-beating organ donation or (2) the decision to withdraw cardiopulmonary support in the context of an anticipated imminent cardiac arrest (death) in nonheart-beating organ donation [6].

\section{Tensions Between End-of-Life Care and Organ Donation in Children}

Healthcare professionals refer children as potential donors in end-of-life trajectory when considered to be imminently dying $[4,5]$. The information disclosed to assist with decision-making on donation is selectively limited to emphasize the benefits of organ transplantation and maximize the consent rate [7-9]. Transplant advocates have recommended "all children on end-of-life care should be referred for potential organ donation" to maximize the supply of transplantable organs in the UK [5]. This is known as "required referral" [5]. To that effect, a UK survey of parents of children that mostly died from neurologic disorders recommended routine integration of early parental discussion of organ donation regardless of donation eligibility in end-of-life care $[10,11]$. End-oflife care begins when healthcare professionals and parents mutually agree on realignment of the child's goals of care to focus on palliative instead of curative treatment. Healthcare professionals can discuss and provide information about donation in the planning phase of endof-life care. In this phase of end-of-life trajectory, the child is not considered imminently dying for referral as a potential donor. Healthcare professionals' discussion of donation, without transparent disclosure of contemporary UK challenges to children end-of-life care, could be easily misunderstood by parents as an implied unconditional endorsement of donation practice to increase the consent rate and the availability of transplantable organs. This commentary highlights: (1) the limitations of the parental survey and (2) the contemporary challenges to end-of-life donation practice that should be addressed appropriately to avoid potential harm to children and parents. This underscores that healthcare professionals have ethical and legal obligations to be fully transparent and non-biased in disclosure of all relevant information when discussing donation to ensure informed parental decision-making.

\section{Parental Discussion of Organ Donation}

A UK multicenter study surveyed twenty-four parents of children who died in neonatal, pediatric and cardiac intensive care units as well as in children's hospice between 2011 and 2014 and forty-one healthcare professionals that provided end-of-life care [10]. Most of the children died from neurologic disorders secondary to congenital or acquired brain injuries. The neurologic diagnoses included brain tumors, spinal muscular atrophy, preterm birth with brain damage, and cerebral palsy. Parents were surveyed through telephone interviews, and the healthcare professionals were interviewed in focus groups [10]. Authors concluded, "[w] hen OTD [organ and tissue donation] is not raised, parents can make assumptions about the value of their child's organs. Donation should be discussed, regardless of eligibility for donation" [10]. The integration of routine parental discussion of donation regardless of donation eligibility is congruent with the objective that "[a]ll children on endof-life care should be referred for potential organ donation" [5]. However, the demographic characteristics of the parents did not support the generalizability of the conclusion because: (1) only one-quarter of the eligible cohort of parents were included, while the remaining parents were excluded because of difficult interactions with the clinical team, court cases, or other difficulties that were sensitive to disclose, (2) parents were mostly White British or European ethnic background, and (3) the religious affiliation of the parents was not included in the survey [10]. The Royal College of Paediatrics and Child Health, however, has underscored the importance of considering parental ethnicity and religious affiliations in the UK practice guidelines for end-of-life care in children [12]. Furthermore, there are unresolved medical, legal, cultural, and religious challenges to end-of-life donation in neurologic disorders that can generate parental conflict with healthcare professionals in the UK. These challenges should be disclosed in donation discussions with parents.

\section{Medical Challenges}

Children with neurologic disorders secondary to congenital or acquired severe brain injuries are generally eligible for donating transplantable organs. Before referral as potential donors, healthcare professionals are required to determine with reasonable clinical certainty that severe brain injuries in these children are either survivable with poor quality of life because of severe neurologic disabilities or non-survivable because of death declaration by brain(stem) criteria. However, what informs healthcare professionals' prediction of poor neurologic outcome or diagnosis of death by brain(stem) criteria in children with severe brain injuries?

Advances in neuroscience have improved contemporary understanding of disorders of consciousness after severe brain injuries over the past two decades [13-16]. Phenomena such as neuronal ischemic preconditioning, global ischemic penumbra, neurogenesis, and neuroplasticity have been discovered in the developing and adult human brain [17]. Neuroscience advances have also enabled the detection of covert consciousness and facilitated the development of new therapeutic 
interventions and neurorehabilitation programs to assist neurologic recovery after severe brain injuries [14-16]. The 2018 American Academy of Neurology's clinical practice guidelines have outlined and encouraged the inclusion of diagnostic and therapeutic advances in the treatment of severe brain injuries [18]. The guidelines caution against premature withdrawal and withholding of treatment following severe brain injuries because of uncertainty about the capacity and the timeline of the human brain to recover following severe injury and consequently the difficulty of accurately predicting the long-term neurologic outcome. This is most pertinent in children because the updated guidelines in severe brain injuries can improve the accuracy of clinical decisionmaking and prevent inappropriate withholding and/or withdrawing of treatment and inappropriate referral as potential end-of-life organ donors. In contrast, the 2013 UK practice guidelines for prolonged disorders of consciousness have not incorporated new diagnostic and therapeutic modalities in the management of severe brain injuries $[19,20]$. The scientific reliability of the UK practice guidelines can have profound consequences on clinical decision-making and timing of withdrawal and/or withholding of life-support treatment and other potentially beneficial neurotherapeutic interventions following severe brain injuries $[14,15,20-22]$. The inclusion of a multimodal approach of functional neuroimaging, neuroelectrophysiological studies, and advanced neuroimaging technology with command-following or naturalistic paradigms can improve the diagnostic accuracy of the UK guidelines for the detection of covert consciousness in prolonged disorders of consciousness [23-25]. Improved diagnostic accuracy can prevent therapeutic nihilism among healthcare professionals and premature termination of treatment and may enable implementation of pharmacologic (e.g., amantadine, zolpidem, etc.) and non-pharmacologic (e.g., transcranial magnetic stimulation, deep brain stimulation, etc.) interventions that can assist with recovery of consciousness [14]. Likewise, the 1976 UK Code of practice for the diagnosis and confirmation of death established brain(stem) criteria (coma or behavioral unresponsiveness, brainstem areflexia, and apnea) for the diagnosis of death after severe brain injuries [6]. These clinical diagnostic criteria have remained unchanged in the 2010 updated Code of practice although neuroscience discoveries have refuted the equivalency of the stipulated brain(stem) criteria with death $[17,21,22,26]$. This is problematic because false positive diagnosis of death has been reported after applying the brain(stem) criteria in children [21, 27-31]. Error in the declaration of death can threaten parental trust in healthcare professionals as treatment may be discontinued prematurely in a child with the potential to survive
[32]. If organ donation is discussed with parents early in end-of-life trajectory of children with neurologic disorders, the desire to accelerate donation and procurement of transplantable organs may influence the process of clinical decision-making on foregoing treatment and compromise the integrity of the healthcare professionalparent relationship. In summary, the contemporary UK practice guidelines for defining treatment futility and diagnosis of death with brain(stem) criteria in children with severe brain injuries need to be updated and revised to avoid premature discontinuation of treatment and/or incorrect declaration of death and proceeding with organ donation.

\section{Legal Challenges}

Parental consent is required in children under the age of 18 years for end-of-life organ donation in the UK because deemed (presumed) consent only applies to adults [2]. However, the Children Act 1989 allows the UK judicial system to apply the test of best interests of a child in the initiation and/or (dis)continuation of life-support treatment and/or non-palliative interventions in end-of-life care, irrespective of parental consent [33]. This test was relevant in several publicized UK cases in which the courts opined in favor of non-consensual withholding and/or withdrawal of life-support treatment in children at the end of life. These cases included MK, 8-month-old girl born with hypo-plastic left-heart syndrome (Great Ormond Street Hospital v NO \& KK \& Ors) [34], Charlie Gard, 9-month-old boy with congenial neuromuscular degenerative disorder (Great Ormond Street Hospital $v$ Yates \& Ors) [35], and Alfie Evans, 23-month-old boy with congenital neurodegenerative disorder (Alder Hey Children's NHS Foundation Trust v Evans \& Ors) [36]. Healthcare professionals argued successfully that the initiation and/or continuation of life-support treatment including cardiopulmonary resuscitation, mechanical ventilation, enteral nutrition, and hydration were nonpalliative and would inflict additional pain and suffering in a child's end-of-life care. In the three cases, the courts decided to allow withdrawal and withholding of the aforementioned medical interventions without parental consent as being in the child's best interests [34-36]. If the same legal test of the best interests of a child is applied to organ donation in end-of-life care, then the initiation and/or continuation of non-palliative medical interventions that are necessary to facilitate procurement of transplantable organs would be equally prohibited irrespective of parental consent. Medical interventions may include (but is not limited to) initiation and/or continuation of mechanical ventilation, insertion of arterial and venous vascular catheters/cannulas, and administration of systemic anticoagulation and/or other non-palliative 
medications for organ preservation to maximize the transplantation quality of procured organs. Performing additional medical interventions that are not palliative to the dying child can cause pain and suffering. Integrating routine discussion with parents about the quality and utility of donating organs from their dying children for transplantation regardless of donation eligibility early in end-of-life trajectory raises additional concerns. UK transplant advocates have argued that parental consent is both ethically and legally sufficient to permit antemortem interventions to optimize organ donation in dying children [37, 38]. If parental donation consent is sought and obtained in a child with neurologic disorder who is otherwise ineligible for donation because of the anticipated end-of-life trajectory, healthcare professionals may alter a child's end-life care to fulfill parental donation request. A case in point, a child with brainstem tumor is admitted to hospice for end-of-life care. Donation discussion with the parents indicates the wish to donate their dying child's solid organs for transplantation. When the child neurologically deteriorates and develops acute signs of loss of brainstem functions, parents may request or agree to transfer their child from hospice to an intensive care unit to initiate cardiopulmonary and organ support that enables donation of transplantable organs. Initiating these non-palliative medical interventions to facilitate the candidacy for end-of-life donation can harm the child. Furthermore, false positive diagnosis of death by brain(stem) criteria can raise genuine concerns that certain neurologic functions such as conscious awareness and nociception may have not ceased irreversibly [26, 39, 40]. Subsequent pain and distress can arise from surgical procurement of organs without general anesthesia. To summarize, the best interests of a child and avoidance of pain and suffering at the end of life are the UK legal standard for performing medical interventions in children regardless of parental consent. The best interests' standard would proscribe additional non-palliative interventions in end-of-life care of children for the purpose of procurement of transplantable organs irrespective of parental wishes.

\section{Cultural and Religious Challenges}

The UK is a pluralistic society with diverse cultural and religious affiliations [41]. Many cultures and religions uphold certain fundamental values about the inviolability of human life and dignity that are incompatible with the logistics and procedures required for successful end-of-life organ donation (e.g., donor preparation, organ preservation, withdrawal of life-support, criteria of death, etc.) [26, 42, 43]. Some advocates have argued against accommodating parental religious values if they conflict with end-of-life decision-making and/or death determination by brain(stem) criteria stating that "religious beliefs should" not "be allowed to stonewall a secular approach to withdrawing and withholding treatment in children" [41, 44]. This intractable parental conflict with healthcare professionals on end-of-life treatment withdrawal or death declaration by brain(stem) criteria on religious grounds will also exclude these children from candidacy for organ donation. Failure of healthcare professionals to accommodate religious values of parents in the end-of-life care of their children can have a profound negative impact on surviving family members $[12,26,39,43]$. Other commentators have suggested that donating a child's organs can be a coping mechanism to deal with death as well as lessen parental grief symptoms [45]. This narrative may be suggested in an effort to negate potential conflict with parental cultural values [46]. There are no well-controlled studies substantiating that organ donation is a parental coping mechanism that will necessarily diminish the grief symptoms after a child's death. Indeed, clinical research did not report differences in the symptom burden when comparing grief symptoms in deceased donors and non-donors family members [47]. Other research has also indicated that grief symptoms can be aggravated in surviving family members of donors if they had doubt about the death diagnosis by brain(stem) criteria [48]. This calls for future clinical studies to elucidate the potential adverse psychosocial effects of routine donation discussion and referral on surviving family members. To sum up, the routine integration of donation discussion and referral regardless of eligibility in the end-of-life care of children can disregard diverse cultural and religious values with possible negative long-term psychosocial consequences on surviving parents and family members.

\section{Conclusions}

The integration of routine referral of all children with severe neurologic disorders for potential end-of-life organ donation ignores contemporary medical, legal, cultural, and religious challenges in the UK. This underscores that healthcare professionals have ethical and legal obligations to be fully transparent and non-biased in disclosure of all relevant information when discussing donation to ensure informed parental decision-making. It is recommended that: (1) practice guidelines for the diagnosis and treatment of neurologic disorders following severe brain injuries in children are updated and aligned with recent advances in neuroscience to avoid potential errors from premature treatment discontinuation and/ or incorrect diagnosis of death by brain(stem) criteria, and (2) a transparent societal dialogue is commenced to address the legal, cultural, and religious consequences of routine integration of organ donation in end-of-life care 
of children. If the contemporary challenges are resolved appropriately and donation discussions are fully transparent and non-biased with decision-makers, then referral for donation in end-of-life care is less likely to harm children and parents.

\section{Author contributions}

MYR authorship credit is based on: (1) substantial contributions to conception and design, or analysis and interpretation of data; (2) drafting the article or revising it critically for important intellectual content; and (3) final approval of the version to be published.

\section{Source of support}

The author received no financial grant for the research, authorship, and/or publication of this article.

\section{Conflicts of Interest}

The author(s) declared no potential conflicts of interest with respect to the research, authorship, and/or publication of this article.

\section{Ethical approval/Informed consent}

This article does not contain any studies with human or animal participants. There is no informed consent because this article does not contain any studies with human participants

\section{Publisher's Note}

Springer Nature remains neutral with regard to jurisdictional claims in published maps and institutional affiliations.

Published online: 22 May 2020

\section{References}

1. lacobucci G. Organ donation: England will have "opt-out" system from May 2020. BMJ. 2020;368:m752.

2. National Health Service Blood and Transplant. English organ donation law is changing from 20 May 2020. What is the opt out system in England? 2020 [cited 23 April 2020]. https://www.organdonation.nhs.uk/.

3. Human Tissue Authority The regulator for human tissue and organs. Government confirms organ donation system change in England on 20 May. 2020 [cited 23 April 2020]. https://www.hta.gov.uk/news/government -confirms-organ-donation-system-change-england-20-may.

4. National Institute for Health and Care Excellence (NICE). Organ donation for transplantation: improving donor identification and consent rates for deceased organ donation. Published date: 12 December 2011 Last updated: 21 December 2016. 2011 [cited 23 April 2020]. https://www. nice.org.uk/guidance/cg135/chapter/1-Recommendations\#identifyin g-patients-who-are-potential-donors.

5. Carone L, Alurkar S, Kigozi P, Vyas H. Organ and tissue donation in a regional paediatric intensive care unit: evaluation of practice. Eur J Pediatr. 2018;177(5):709-14

6. The Academy of Medical Royal Colleges. A code of practice for the diagnosis and confirmation of death. A report of the Academy of Medical Royal Colleges. Updated online August 10, 2010. 2008 [cited 23 April 2020]. http://www.aomrc.org.uk/publications/reports-guidance/ukdec -reports-and-guidance/code-practice-diagnosis-confirmation-death/.

7. Simpkin AL, Robertson LC, Barber VS, Young JD. Modifiable factors influencing relatives' decision to offer organ donation: systematic review. BMJ. 2009;338:b991.

8. Shafer TJ. Improving relatives' consent to organ donation. BMJ. 2009:338:b701.

9. Rady MY, McGregor JL, Verheijde JL. Mass media campaigns and organ donation: managing conflicting messages and interests. Med Health Care Philos. 2012;15(2):229-41.
10. Darlington A-S, Long-Sutehall T, Randall D, et al. Parents' experiences of requests for organ and tissue donation: the value of asking. Arch Dis Child. 2019;104(9):837-43.

11. Bratton SL, Zollinger CM. Bereaved ICU parental end-of-life care goals: including organ donation regardless of eligibility. Arch Dis Child. 2019;104(9):823-4.

12. Larcher V, Craig F, Bhogal K, et al. Making decisions to limit treatment in life-limiting and life-threatening conditions in children: a framework for practice. Arch Dis Child. 2015;100(Suppl 2):s1-23.

13. Giacino JT, Katz DI, Schiff ND, et al. Comprehensive systematic review update summary: disorders of consciousness. Report of the Guideline Development, Dissemination, and Implementation Subcommittee of the American Academy of Neurology; the American Congress of Rehabilitation Medicine; and the National Institute on Disability, Independent Living, and Rehabilitation Research. Neurology. 2018;91(10):461-70.

14. Thibaut A, Schiff N, Giacino J, Laureys S, Gosseries O. Therapeutic interventions in patients with prolonged disorders of consciousness. Lancet Neurol. 2019;18(6):600-14.

15. Owen AM. The search for consciousness. Neuron. 2019;102(3):526-8.

16. Claassen J, Doyle K, Matory A, et al. Detection of brain activation in unresponsive patients with acute brain injury. N Engl J Med. 2019;380(26):2497-505

17. Verheijde $J$, Rady MY, Potts M. Neuroscience and brain death controversies: the elephant in the room. J Relig Health. 2018;57(5):1745-63.

18. Giacino JT, Katz DI, Schiff ND, et al. Practice guideline update recommendations summary: disorders of consciousness. Report of the Guideline Development, Dissemination, and Implementation Subcommittee of the American Academy of Neurology; the American Congress of Rehabilitation Medicine; and the National Institute on Disability, Independent Living, and Rehabilitation Research. Neurology. 2018;91(10):450-60.

19. Royal College of Physicians of London. Prolonged disorders of consciousness: National clinical guidelines. London, RCP. 2013 [cited 23 April 2020]. http://www.rcplondon.ac.uk/resources/prolonged-disorders-consciousn ess-national-clinical-guidelines.

20. Rady MY, Verheijde JL. Nonconsensual withdrawal of nutrition and hydration in prolonged disorders of consciousness: authoritarianism and trustworthiness in medicine. Philos Ethics Humanit Med. 2014;9(1):16.

21. Machado C, DeFina PA, Estévez $M$, et al. A reason for care in the clinical evaluation of function on the spectrum of consciousness. J Funct Neurol Rehabilit Ergonomics. 2017;7(4):89-99.

22. Shewmon DA. Truly reconciling the case of Jahi McMath. Neurocrit Care. 2018;29(2):165-70

23. Sinai L, Owen AM, Naci L. Mapping preserved real-world cognition in severely brain-injured patients. Front Biosci (Landmark Ed). 2017;22:815-23.

24. Rady MY, Verheijde JL. Judicial oversight of life-ending withdrawal of assisted nutrition and hydration in disorders of consciousness in the United Kingdom: a matter of life and death. Med Leg J. 2017;85(3):148-54.

25. Owen AM. Improving diagnosis and prognosis in disorders of consciousness. Brain. 2020;143(4):1050-3.

26. Choong KA, Rady MY. Re A (A Child) and the United Kingdom Code of practice for the diagnosis and confirmation of death: should a secular construct of death override religious values in a pluralistic society? HEC Forum. 2018:30(1):71-89.

27. Joffe AR, Anton NR. Some questions about brain death: a case report. Pediatr Neurol. 2007;37(4):289-91.

28. Joffe AR, Kolski H, Duff J, deCaen AR. 10-Month-old infant with reversible findings of brain death. Pediatr Neurol. 2009;41(5):378-82.

29. Joffe AR, Kolski H, Duff J, deCaen A. Response: are brain death findings reversible? Pediatr Neurol. 2010;42(4):306-7.

30. Shewmon DA. False-positive diagnosis of brain death following the pediatric guidelines: case report and discussion. J Child Neurol. 2017;32(14):1104-17.

31. Hansen G, Joffe AR. Confounding brain stem function during pediatric brain death determination: two case reports. J Child Neurol. 2017;32(7):676-9.

32. Lazaridis C. Withdrawal of life-sustaining treatments in perceived devastating brain injury: the key role of uncertainty. Neurocrit Care. 2019;30(1):33-41. 
33. Children Act 1989. http://www.legislation.gov.uk/ukpga/1989/41/conte nts.

34. Great Ormond Street Hospital for Children Foundation NHS Trust v NO \& KK \& Ors [2017] EWHC 241 (Fam) (14 February 2017). http://www.baili i.org/ew/cases/EWHC/Fam/2017/241.html.

35. Great Ormond Street Hospital v Yates \& Ors [2017] EWHC 972 (Fam) (11 April 2017). http://www.bailii.org/ew/cases/EWHC/Fam/2017/972.html.

36. Alder Hey Children's NHS Foundation Trust v Evans \& Ors [2018] EWHC 818 (Fam) (11 April 2018). http://www.bailii.org/ew/cases/EWHC/ Fam/2018/818.html.

37. Brierley J. Neonatal organ donation: has the time come? Arch Dis Child Fetal Neonatal Ed. 2011;96(2):F80-3.

38. Brierley J, Shaw D. Premortem interventions in dying children to optimise organ donation: an ethical analysis. J Med Ethics. 2016;42(7):424-8.

39. Nair-Collins M. Can the brain-dead be harmed or wronged?: On the moral status of brain death and its implications for organ transplantation. Kennedy Inst Ethics J. 2017;27(4):525-59.

40. Joffe AR, deCaen A, Garros D. Misinterpretations of guidelines leading to incorrect diagnosis of brain death: a case report and discussion. J Child Neurol. 2019;35(1):49-54.

41. Brierley J, Linthicum J, Petros A. Should religious beliefs be allowed to stonewall a secular approach to withdrawing and withholding treatment in children? J Med Ethics. 2013;39(9):573-7.
42. Jones DA. Loss of faith in brain death: Catholic controversy over the determination of death by neurological criteria. Clin Ethics. 2012;7(3):133-41.

43. Gabbay E, Fins JJ. Go in peace: brain death, reasonable accommodation and jewish mourning rituals. J Relig Health. 2019;58(5):1672-86.

44. Brierley J. UK court accepts neurological determination of death. The Lancet. 2015;385(9984):2254.

45. Ashkenazi T, Cohen J. Interactions between health care personnel and parents approached for organ and/or tissue donation: influences on parents' adjustment to loss. Progress in Transplantation. 2015;25(2):124-30.

46. Stouder DB, Schmid A, Ross SS, Ross LG, Stocks L. Family, friends, and faith: how organ donor families heal. Prog Transplant. 2009;19(4):358-61.

47. Bellali T, Papadatou D. Parental grief following the brain death of a child: does consent or refusal to organ donation affect their grief? Death Stud. 2006;30(10):883-917.

48. Kentish-Barnes N, Chevret S, Cheisson G, et al. Grief symptoms in relatives who experienced organ donation requests in the ICU. Am J Respir Crit Care Med. 2018;198(6):751-8. 